\title{
A Study on Development of Dual Locking Linkage for Landing Gear for the Application to UAV
}

\author{
Sung Hoon Oh \\ Division of Mechanical system engineering, Chon-buk National University, \\ Dukjin-dong, Jeon-ju city, Jeollabuk-do, 561-756 \\ oshun0305@jbnu.ac.kr
}

\begin{abstract}
Importance of landing device in the development of unmanned aircraft, the use of which is increasing for various purposes such as environment monitoring, is being raised. In this research, we devised folding type landing device which can be applied to unmanned aircraft and other various aviation equipment. In this model, we developed a linkage module which had independent locking function in the operation of landing gear, and applied one actuator to reduce the weight and volume. The applied actuator is developed as a form of applying a ball screw with free wheel function to prevent damage due to mechanical crash and a worm gear type reducer of 20:1 reduction ratio. Downlock linkage can stand the impulsive load of 1 ton or more to prevent folding by the impact at time of landing, uplock linkage was verified of the safety through the dynamic behavior analysis and static behavior analysis of the linkage to prevent the folded linkage from unfolding. We evaluated the suitability of the landing device through the landing test of developed linkage module.
\end{abstract}

Keywords: Actuator, Landing gear, Unmanned Aerial Vehicle, Linkage

\section{Introduction}

Unmanned Aerial Vehicle (UAV) refers to the flight vehicle that flies autonomously devoid of a pilot in accordance to the pre-input program while flight vehicle itself recognizes the surrounding environment and makes judgment.

Unmanned Aerial Vehicle (UAV) that was developed in the past and that is used today is utilized mostly for military purpose such as surveillance, reconnaissance, and offensive action. Today, however, the trend is such that the scope of use is expanding to the private sector. It is used in diverse ways such as remote exploration, communication relay and environment surveillance [1-3]. Most of the Unmanned Aerial Vehicles (UAV) that are used today after getting developed takes off by using Launcher and lands by using supplementary equipment such as Arresting Hook, Net, or Parachute. These launch and collection equipment take up about $15 \%$ of the Unmanned Aerial Vehicle (UAV)'s price. Likewise, development cost is increasing [4-6].

Existing landing gear is very limited when it comes to the use at narrow geography without runway or the operation on the runway for movement. During landing process, problems may result such as damage to air frame and equipment. Recently, fixed type of landing gear is being applied, but aircraft operability tends to lag behind since wheels are fixed [7-8]. Moreover, this is limited in terms of design. Folding type of landing gear that is applied to manned aircraft generally uses two hydraulic actuators, but this is difficult to apply in case of Unmanned Aerial Vehicle (UAV) due to its volume and weight whereas lighter and smaller 
device is required.

To reduce volume and weight, this research developed electric actuator with Free wheel function and folding type of landing gear that contains Dual-Lock linkage module.

\section{Dual Locking Linkage Development}

\subsection{Development of electric actuator with Free wheel function}

Unmanned Aerial Vehicle (UAV)'s small fuselage is restricted in terms of weight and space taken up by each device. Thus, it is limited when it comes to the application to hydraulic actuator device. In general, small Unmanned Aerial Vehicle (UAV) provides source of power with DC electricity. Electric actuator that uses DC power is the core module for operating landing gear linkage. As for the motor used for actuator, DC $24 \mathrm{~V}$ is easy to get supplied by small Unmanned Aerial Vehicle (UAV). Thus, it can be operated at DC $24 \mathrm{~V}$. Motor that satisfies EMI environment test was selected to prevent malfunction, resulting from generation of electromagnetic waves of diverse forms when it comes to the Unmanned Aerial Vehicle (UAV)'s numerous electronic equipment. Motor is characterized by the following specs during no-load; revolution speed of 3600RPM, rated torque of $3.77 \mathrm{~kg}-\mathrm{cm}$, rated normal current of $6.5 \mathrm{amp}$ and weight of $1.5 \mathrm{~kg}$. Because motor's size increases when brake function is included, reducer of the worm gear form with reduction gear ratio of 20:1 was selected to replace brake function.

Recti-lineal electric actuator is the source of power for activating linkage subject to development. Screw can convert motor's rotary motion into straight line form motion. Ball screw type with Free wheel function was selected. Free wheel function enables ball nut to rotate at the same place by activating internal mechanism when the ball screw's ball nut collides with stoppage device after reaching screw bolt's set place. Through this, it is possible to prevent origin recognition, and damage resulting from the mechanical collision of the outside cylinder's upper/lower parts while ball nut is at the maximum and minimum points during Unmanned Aerial Vehicle (UAV) operation.

To ensure optimal placement of each part, AL 7075-T6 material was used for actuator housing to apply through $\mathrm{CNC}$ precision processing after casting. Figure 1 shows actuator's form.

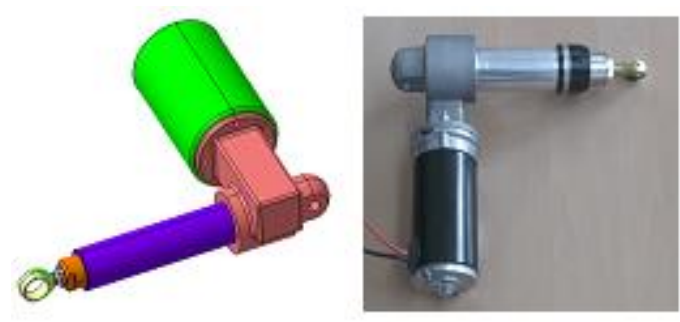

Figure 1. Actuator modeling and production

\subsection{Landing gear linkage module development}

Because development of landing gear for Unmanned Aerial Vehicle (UAV) is not carried out actively worldwide, optimal landing gear linkage design draft was identified by studying similar linkage cases that were applied to the developed manned aircraft in the past.

As for the linkage to be developed, the following functions were provided; folding and unfolding of the linkage by one actuator and Dual-Lock function that locks at each respective 
location. Moreover, to develop into a structure that can withstand 1.0 ton or greater landing shock load, structure that is not subjected to shock load was considered for actuator. This was designed into a structure in which link connection is dismantled at the actuator, while merely linkage is connected to withstand while linkage is unfolded. As for the material used, material of the AL 7071 type that is light and that is characterized by superb strength level was used by factoring in the characteristics of small Unmanned Aerial Vehicle (UAV), and Bush of the brass material was applied on each link rotation part.

\subsubsection{Downlock design}

Downlock's function should maintain linkage at locked state at the time of landing while linkage is completely unfolded and should prevent unfolded linkage from getting folded due to shock during landing. Moreover, Downlock function should operate without affecting linkage's folding and unfolding motions.

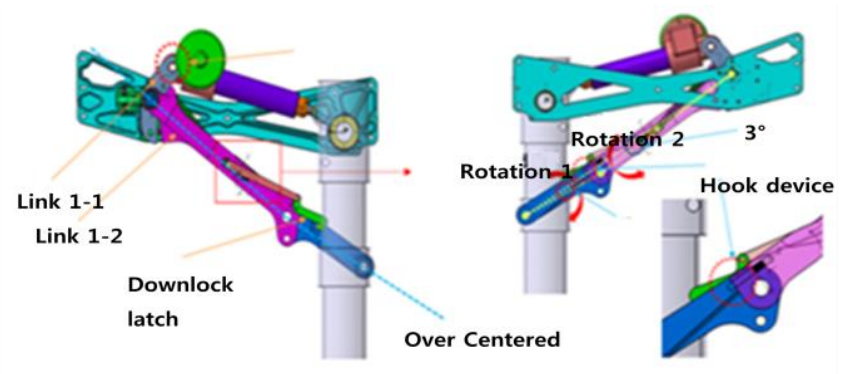

Figure. 2 Over Center design for Downlock

Linkage-1 and Linkage-2 that comprise Main Linkage as shown on Figure 2, should be placed in a way that they form about $3^{\circ} \sim 5^{\circ}$ eccentricity with Over Center concept instead of straight line so that Self Locking can result when shock is transmitted. Figure 3 applied Latch Block that can maintain the Downlock without concern for transmutation or damage resulting from outside shock. This is operated in Cam method to facilitate Downlock function application and dismantling.

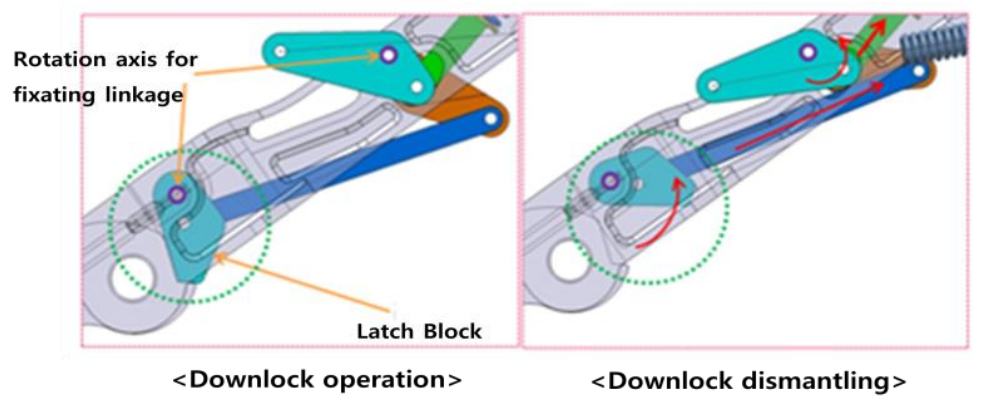

Figure 3. Principle behind operation of Latch Block of the Method

Figure 4 demonstrates Downlock's form. It was ensured that only Downlock's application and dismantling can take place at merely specific motion area among the areas where actuator activates by applying Retaining spring in which spring's actuating force changes to the center, left and right sides of the rotation. Moreover, air pressure spring can be applied to protect the actuator by absorbing the shock resulting at the time of landing by using air pressure and spring. 


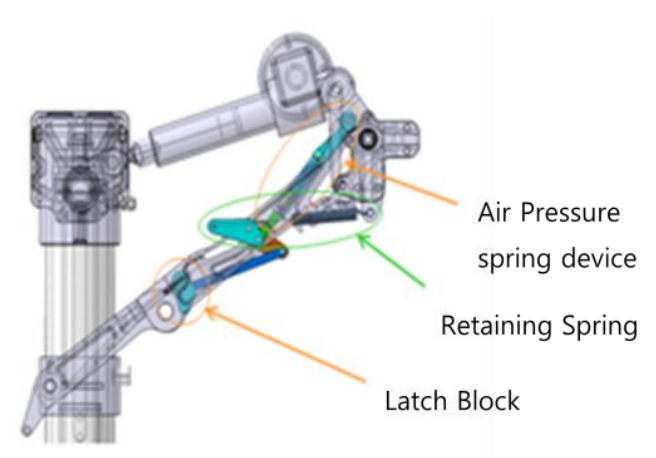

Figure 4. Detailed Downlock modeling

\subsubsection{Uplock design}

Uplock's function prevents the form in which linkage that got folded during aircraft operation after the take-off and does not affect linkage's folding and unfolding motion. Uplock needs to operate.

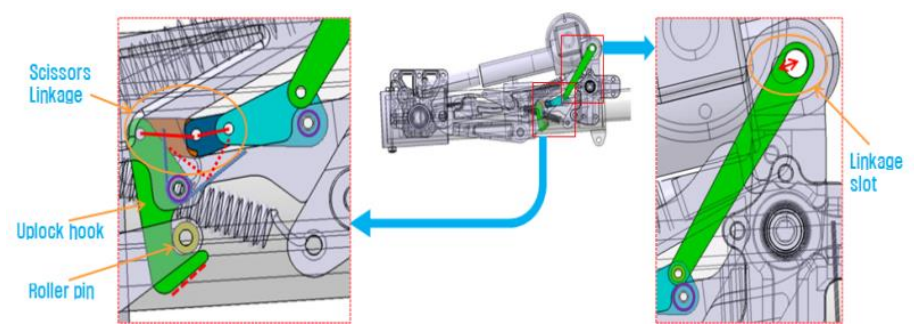

Figure 5. Uplock's detailed modeling

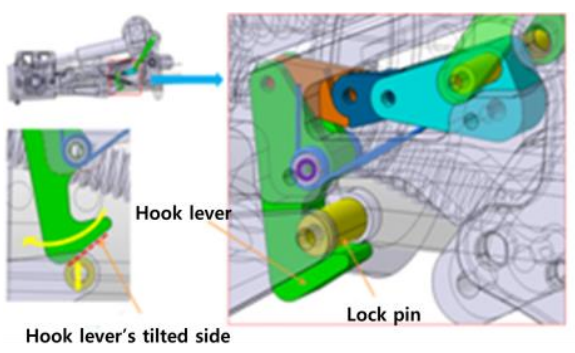

Figure 6. Lever of the Hook method and Lock pin of the Roller method

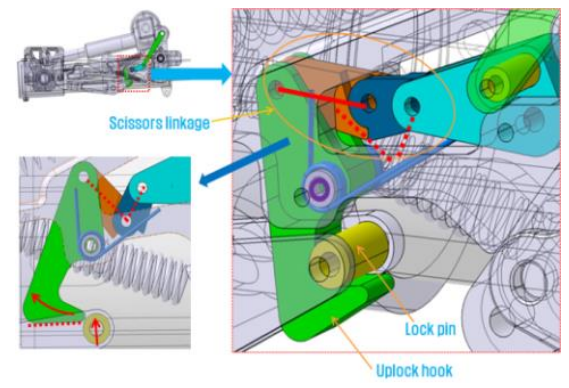

Figure 7. Alternate angles' Scissors Linkage 
Figure 5 demonstrates Uplock's modeling form. Figure 6 applied Lever of Hook method to facilitate UpLock's operation using small power. Moreover, Lock pin of Roller method should be able to push Hook without significant collision since the ends of the Hook are tilted, and Uplock should be made possible. Hook Lever is reinstated to the original position by attaching Uplock retaining spring. Figure 7 enables Hook's rotation with Lock pin to take place independently due to Scissors Linkage of alternate angles. Slot is applied to Actuator lever to dismantle only the Uplock without the movement of linkage in the slot's operation area.

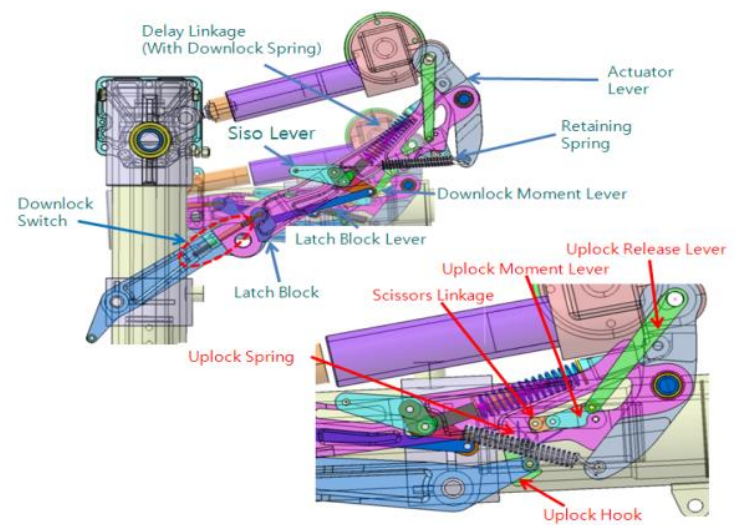

Figure 8. Linkage system's final form and names of each part

\subsection{Linkage structure analysis}

As for the analysis for linkage structure, structure analysis was conducted, targeting the Main Link 1 that receives the most power. Modeling took place with CATIA V5 and modeled solid data was used to conduct dynamic behavior analysis at the ADAMS. By utilizing the dynamic behavior analysis conducted on the ADAMS, value of the load that is granted to link was identified, and this was subjected to test using static load analysis method to verify safety.
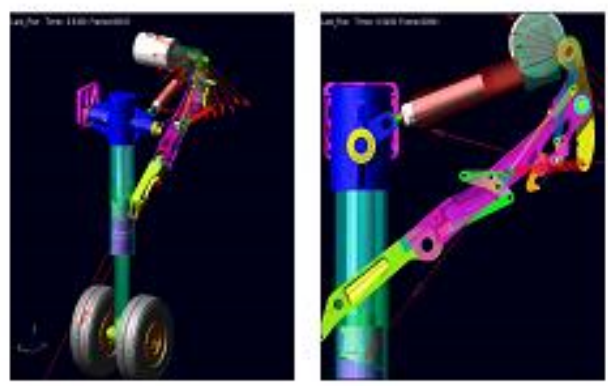

Figure 9. ADAMS analysis for the linkage suspended load that changes during operation

Under analysis condition, load applies landing gear of $14.5 \mathrm{~kg}$, Link 1 of $0.485 \mathrm{~kg}$, Link 2 of $0.27 \mathrm{~kg}$, and landing shock load of $1,000 \mathrm{~kg}$, and flight vibration is not factored in.

To conduct static structure analysis, compression with basic load or tensile load was applied, and moment load was applied additionally onto the basic load with combination load to carry out structure analysis. 


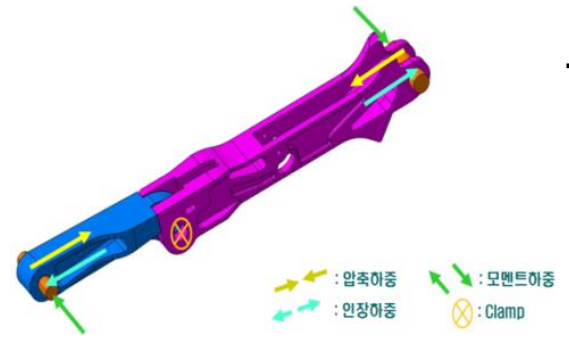

Figure 10. Load application method

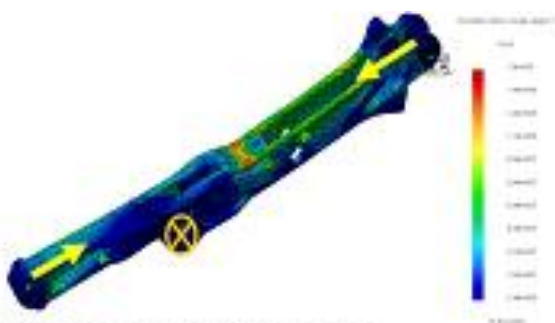

(a)Compressive bad(1260H)

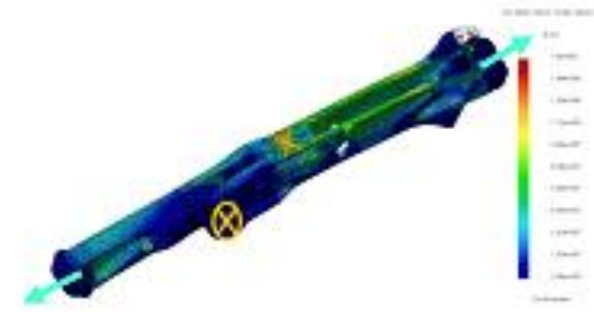

(c)Tersile load (1260N)
Table 1. Results of the static structural analysis

\begin{tabular}{|c|c|c|}
\hline \multicolumn{2}{|c|}{ Load conditions } & $\begin{array}{c}\text { Maximum } \\
\text { stress value }\end{array}$ \\
\hline \multirow{2}{*}{$\begin{array}{c}\text { Compressive } \\
\text { load }\end{array}$} & $12601 \mathrm{~N}$ & $160 \mathrm{MPa}$ \\
\cline { 2 - 3 } & $12601 \mathrm{~N} \times 1.5$ & $241 \mathrm{MPa}$ \\
\hline \multirow{2}{*}{ Tensile load } & $12601 \mathrm{~N}$ & $160 \mathrm{MPa}$ \\
\cline { 2 - 3 } & $12601 \mathrm{~N} \times 1.5$ & $241 \mathrm{MPa}$ \\
\hline
\end{tabular}

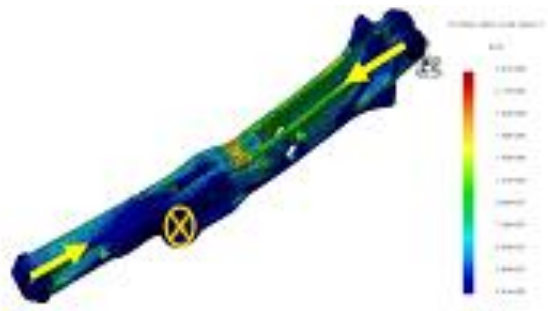

(b) Compre ssive load( $1260 \mathrm{H} \times 1.5$ )

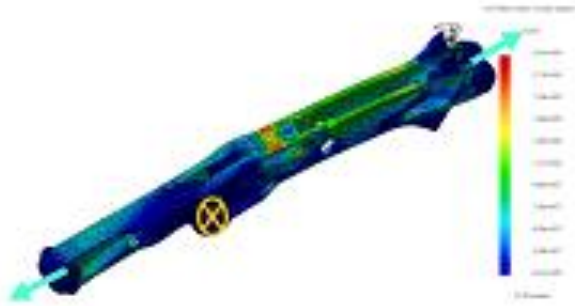

(d)Tensile bad(1260 $\times 1.5$ )

Figure 11. Result of static structural analysis

As for the material property for the applied material, AI7075-T6, yield strength is 470MPa and tensile strength is $535 \mathrm{MPa}$. Structure analysis was conducted which demonstrated structural safety within the scope of the applied material's yield strength and tensile strength. Figure 12 demonstrates produced linkage's form.
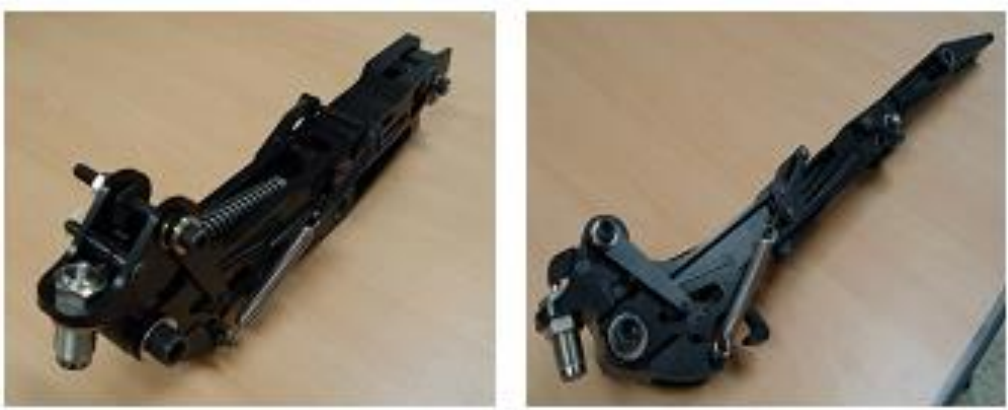

Figure 12. Final linkage production form 


\section{Landing Test}

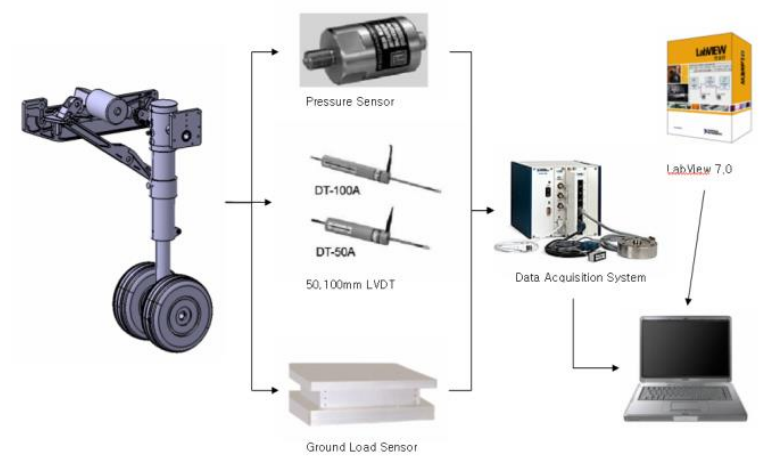

Figure 13. Data Acquisition System's schematic diagram

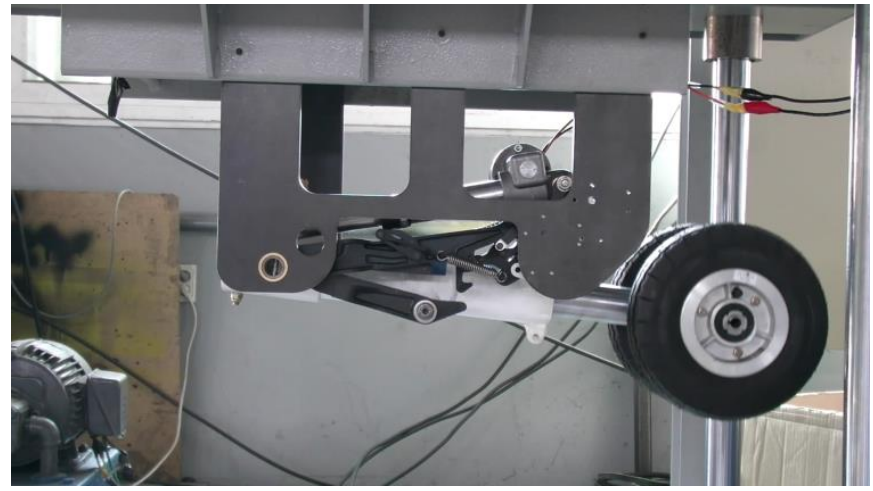

Figure 14. Developed landing gear

Performance of the linkage developed with the equipment composed as shown on Figure 13 was evaluated. Testing device and data acquisition system's schematic diagram was presented. As shown on the diagram, load sensor of 50,100, 200mm displacement sensor and pressure gauge were used for this experiment. Labview was used to carry out Post Processing. In order for the landing gear to measure load during ISO Thermal Test and drop test, MC3232load sensor was applied. Vertical Drop and Oblique Drop were executed on the ground surface for the drop test. Maximum impact drop load was conducted with 1.0 ton.

Figure 14 demonstrates landing gear that reacted linkage and actuator, attached onto the experiment equipment. Folding/unfolding tests and shock load tests were conducted 100 times to assess normal operation while there was not detected intervention among parts or any abnormality. Developed Dual Locking linkage has weight of $9.7 \mathrm{~kg}$ and $5.4 \mathrm{sec}$ operation time. Actuator's thrust was measured at $362 \mathrm{~kg}$. As for the shock load, it can withstand up to 1.4 ton and the left/right landing tilt angle was $12^{\circ}$ while up/low landing tilt angle was $17^{\circ}$.

\section{Conclusion}

This research utilized one electric actuator to develop landing gear that can be applied to the Unmanned Aerial Vehicle (UAV). Actuator that was developed by using Free wheel function can be applied to diverse electric actuators going forth. Moreover, by developing 
linkage module that can ensure independent locking function during each state while folding and unfolding aircraft's landing gear by using developed actuator, it is possible to make the device smaller and lighter which is required of Unmanned Aerial Vehicle (UAV). Through this, application to diverse forms of unmanned and manned landing gears is expected as well.

\section{References}

[1] Z. Wen, Z. Zhi, Z. Qidan and X. Shiyue, "Dynamics Model of Carrier-based Aircraft Landing Gears Landed on Dynamic Deck", Chinese journal of Aeronautics, vol. 22, (2009), pp. 371-379.

[2] F. Bagnoli, F. Dolce, M. Colavite and M.Bernabei, "Fatigue Fracture of a Main Landing gear swinging lever in a civil aircraft", Engineering Failure Analysis, vol. 15, (2008), pp. 755-765.

[3] J. X. Tao, S,. Smith and A. Duff, "The effect of overloading sequences on landing gear fatigue damage", International journal of fatigue, vol. 31, (2009), pp. 1837-1847.

[4] J. P. Lee, "Future Unmanned System Design for Reliable Military Operations", International Journal of Control and Automation, vol. 5, (2012), pp. 173-186.

[5] G. Cai, L. Feng, B. M. Chen and T. H. Lee, "Systematic design Methodology and Construction of UAV Helicopters", Mechatronics, vol. 18, (2008), pp. 545-558.

[6] S. C. Lee, W. R. Lee and K. H. You, "TDoA based UAV Localization using Dual-EKF Algorithm", International Journal of Control and Automation, vol. 2, (2009), pp. 35-42.

[7] H. Khebbache, "Robust Control Algorithm Considering the Actuator Faults for Attitude Tracking of an UAV Quadrotor Aircraft", International Journal of Control and Automation, vol. 5, (2012), pp. 55-66.

[8] Dr. G. Anitha, R. N. Gireesh Kumar, "Vision based autonomous landing of and unmanned aerial vehicle", Procedia Engineering, vol. 38, (2012), pp. 2250-2256.

\section{Authors}

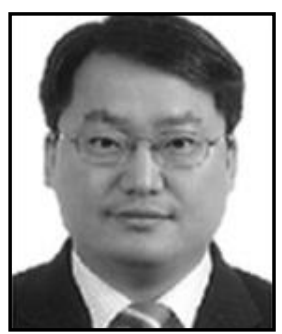

\section{Sung Hoon Oh}

Professor, Division of Mechanical system engineering, Chon-buk National University, Dukjin-dong, Jeon-ju city, Jeollabuk-do, 561756

E-mail: oshun0305@jbnu.ac.kr 